\title{
TESTE DE ENVELHECIMENTO ACELERADO EM SEMENTES DE PIMENTA ${ }^{1}$
}

\author{
MARIACARMENBHERING ${ }^{2}$, DENISE CUNHAFERNANDESDOS SANTOSDIAS ${ }^{3}$, DÉBORAHDE SOUZA VIDIGAL ${ }^{4}$, \\ DANIELDOS SANTOSPORTOCARRERO NAVEIRA ${ }^{4}$
}

\begin{abstract}
RESUMO - O presente trabalho teve por objetivo adequar a metodologia do teste de envelhecimento acelerado para a avaliação do vigor de sementes de pimenta. Sementes de seis lotes foram submetidas aos testes de germinação, primeira contagem de germinação, germinação a baixa temperatura e envelhecimento acelerado. Para o teste de envelhecimento acelerado, foram testados os métodos tradicional (100\% UR) e modificado ( $76 \%$ UR), nas temperaturas de 38 , 42 e $45^{\circ} \mathrm{C}$ durante os períodos de 48, 72 e 96 horas. O teste de envelhecimento acelerado é eficiente para avaliação do vigor das sementes de pimenta, fornecendo informações semelhantes às obtidas na primeira contagem de germinação e germinação a baixa temperatura quando conduzido a $38 \mathrm{ou}$ $42^{\circ} \mathrm{C}$ por 96 horas, tanto pelo método tradicional como pelo método modificado.
\end{abstract}

Termos para indexação: Capsicum frutescens, qualidade fisiológica, vigor, germinação.

\section{ACCELERATEDAGING OF PEPPER SEEDS}

\begin{abstract}
The objective of this study was to adequate the methodology of accelerated aging test for vigor evaluation of pepper seeds. Six seed lots of pepper were tested for germination, germination at first count, cool germination and accelerated aging. For accelerated aging, the following methods were tested: traditional $(100 \% \mathrm{RH})$ and $\operatorname{modified}(76 \% \mathrm{RH})$, at 38,42 and $45^{\circ} \mathrm{C}$ for 48,72 and 96 hours. The accelerated aging test was efficient for vigor evaluation of pepper seeds producing results similar to the first count and cool germination test, especially when conducted at 38 or $42^{\circ} \mathrm{C}$ for 96 hours by both traditional and modified methods.
\end{abstract}

Index terms: Capsicum frutescens, physiological quality, vigor, germination.

\section{INTRODUÇÃO}

O vigor das sementes é reflexo de um conjunto de características que determinam seu potencial fisiológico, ou seja, a capacidade de apresentar desempenho adequado quando expostas a diferentes condições de ambiente. Dada sua importância, vários métodos têm sido propostos visando a avaliação do potencial fisiológico das sementes (Marcos Filho,1999), de modo a obter estimativa segura do desempenho dos lotes de sementes no campo e/ou armazenamento.

Dentre os diferentes testes de vigor disponíveis na atualidade, o de envelhecimento acelerado tem apresentado

\footnotetext{
${ }^{1}$ Submetido em 05/12/2005. Aceito para publicação em 07/06/2006;

${ }^{2}$ Pesquisadora, MSc., Departamento de Fitotecnia, UFV, CEP: 36570-000, Viçosa-MG;
}

resultados confiáveis, uma vez que avalia o comportamento das sementes quando submetidas a condições de estresse, procurando, assim, estimar o potencial relativo de armazenamento dos lotes, apresentando resultados relacionados à emergência de plântulas em campo (Delouche \& Baskin, 1973). Este teste tem como base o fato de que a taxa de deterioração das sementes é aumentada consideravelmente pela sua exposição a temperatura e umidade relativa elevadas, sendo estes os fatores ambientais mais relacionados à deterioração das sementes. Desse modo, lotes de sementes com alto vigor manterão sua viabilidade após serem submetidos ao estresse, enquanto os de baixo vigor terão sua viabilidade reduzida (AOSA, 1983).

\footnotetext{
${ }^{3}$ Professor Adjunto, D.Sc., Departamento de Fitotecnia, UFV, CEP: 36570 000, Viçosa-MG;

${ }^{4}$ Estudante de Agronomia, Departamento de Fitotecnia, UFV, CEP: 36570
} 000, Viçosa - MG. 
O teste de envelhecimento acelerado é um dos mais utilizados pela maioria dos pesquisadores nacionais (Mello e Tillmann, 1987), sendo aplicável a grande número de espécies. Este teste vem sendo estudado em sementes de algumas espécies olerícolas como cebola (Piana et al., 1995), quiabo (Torres e Carvalho, 1998), cenoura (Spinola et al., 1998; Rodo et al., 2000), pimentão (Panobianco e Marcos Filho, 1998), cenoura, alface e brócolos (Ribeiro, 2000), tomate (Rodo et al., 1998; Panobianco e Marcos Filho, 2001), pepino (Bhering et al., 2000), melancia (Bhering et al., 2003), rúcula (Ramos et al., 2004), alface (Franzin et al., 2004). No entanto, são escassas as informações sobre sua utilização para a avaliação do vigor de sementes de pimenta. Segundo Marcos Filho (1999), a pesquisa deve fornecer subsídios para o esclarecimento de dúvidas como, por exemplo, as combinações de temperatura e tempo de exposição para as diferentes espécies.

Para espécies com sementes pequenas, como a maioria das hortaliças, o teste de envelhecimento acelerado pode apresentar certas limitações. Sementes pequenas absorvem água mais rápida e desuniformemente durante o período de envelhecimento, o que pode acelerar o processo de deterioração ou resultar em comportamento variável entre as sementes de uma amostra, interferindo na precisão dos resultados. Em virtude deste fato, Jianhua e McDonald (1996), propuseram um método modificado, envolvendo o uso de soluções salinas saturadas em substituição à água, o que permite reduzir a umidade relativa a qual as sementes são expostas durante o teste. Conseqüentemente, a absorção de água pelas sementes é retardada e o processo de deterioração é menos drástico. Este método mostrou-se eficiente para avaliação do vigor de sementes de milho-doce (Bennett et al., 1998), pimentão (Panobianco e Marcos Filho, 1998), pepino (Bhering et al., 2000), cenoura (Rodo at al., 2000), tomate (Panobianco e Marcos Filho, 2001), melão (Torres e Marcos Filho, 2003) e rúcula (Ramos et al., 2004). Em contrapartida, este procedimento não se mostrou adequado para a avaliação do vigor de sementes de alface, brócolos e cenoura (Ribeiro e Carvalho, 2001) e de melancia (Bhering et al., 2003).

O presente trabalho teve como objetivo adequar a metodologia do teste de envelhecimento acelerado para a avaliação do vigor de sementes de pimenta.

\section{MATERIAL E MÉTODOS}

O experimento foi conduzido no Laboratório de Sementes do Departamento de Fitotecnia da Universidade Federal de
Viçosa, em Viçosa - MG, utilizando-se seis lotes de sementes de pimenta (Capsicum frutescens L.). Foram realizados os seguintes testes e determinações: grau de umidade - realizado pelo método da estufa a $105 \pm 3^{\circ} \mathrm{C}$, utilizando-se duas subamostras para cada lote, sendo os resultados expressos em porcentagem (bu) (Brasil, 1992); germinação - realizado com quatro subamostras de 50 sementes, distribuídas sobre papel germitest umedecido com quantidade de água igual a 2,2 vezes seu peso seco. Foram confeccionados rolos, mantidos em germinador a $25^{\circ} \mathrm{C}$, sendo as avaliações realizadas aos sete e 12 dias após a semeadura. Os resultados foram expressos em porcentagem de plântulas normais obtidas no $12^{\circ}$ dia (Brasil, 1992); primeira contagem de germinação - realizada simultaneamente ao teste de germinação, considerando-se a porcentagem de plântulas normais obtidas no sétimo dia após a semeadura; germinação a baixa temperatura - utilizou-se o mesmo procedimento descrito para o teste de germinação, porém utilizando-se a temperatura de $18^{\circ} \mathrm{C}$. O substrato utilizado, papel germitest, foi umedecido com quantidade de água igual a 2,2 vezes o seu peso seco e mantido em incubadora $\mathrm{BOD}$, a $18^{\circ} \mathrm{C}$, por 24 horas antes de se iniciar o teste. Após a semeadura, foram confeccionados os rolos que foram acondicionados em sacos plásticos e mantidos em incubadora BOD a $18^{\circ} \mathrm{C}$ (Dias e Alvarenga, 1999). Foi realizada uma única avaliação, aos dez dias após a semeadura, considerando como plântulas normais aquelas que apresentaram comprimento igual ou acima de 2,5cm; os resultados foram expressos em porcentagem; emergência de plântulas - conduzido em sala de crescimento de plântulas sob temperatura ambiente média de $25^{\circ} \mathrm{C}$. Foram utilizadas quatro subamostras de 50 sementes, distribuídas em bandejas plásticas de $24 \times 30 \times 6 \mathrm{~cm}$ contendo substrato organo-mineral Plantimax $^{\circledR}$ HA, suficientemente umedecido. As irrigações foram realizadas sempre que necessário. Os resultados foram expressos em porcentagem de plântulas normais obtidas aos 12 dias após a semeadura; envelhecimento acelerado (método tradicional) - adotou-se a metodologia recomendada pela AOSA (1983) e complementada por Marcos Filho (1999). Uma única camada de sementes foi colocada sobre tela metálica acoplada à caixa plástica gerbox, contendo $40 \mathrm{~mL}$ de água ao fundo. As caixas foram tampadas, de modo a obter $100 \%$ UR em seu interior, sendo mantidas em incubadora BOD a 38, 42 e $45^{\circ} \mathrm{C}$, durante 48, 72 e 96 horas. Decorrido cada período, quatro subamostras de 50 sementes foram colocadas para germinar, seguindo método descrito para o teste de germinação. Uma única avaliação foi realizada no oitavo dia após a semeadura, computando-se a porcentagem de 
plântulas normais; envelhecimento acelerado com o uso de solução salina saturada - utilizou-se a metodologia descrita para o método tradicional, porém, substituindo-se a água no interior das caixas gerbox por $40 \mathrm{~mL}$ de solução saturada de $\mathrm{NaCl}$ (40g de $\mathrm{NaCl}$ em $100 \mathrm{~mL}$ de água), obtendose assim ambiente com $76 \%$ de UR, conforme descrito por Jianhua e McDonald (1996).

Após o envelhecimento acelerado (tradicional e modificado), o grau de umidade das sementes foi determinado pelo método da estufa a $105 \pm 3^{\circ} \mathrm{C}$ por 24 horas, sendo os resultados expressos em porcentagem (bu).

O delineamento experimental utilizado foi o inteiramente casualizado com quatro repetições. Para cada teste, a comparação entre as médias obtidas para cada lote foi feita pelo teste de Tukey a 5\% de probabilidade. Os dados referentes ao grau de umidade das sementes não foram submetidos à análise estatística.

\section{RESULTADOS E DISCUSSÃO}

Na Tabela 1, encontram-se os resultados referentes aos testes de germinação, primeira contagem de germinação e germinação a baixa temperatura. Pelo teste de germinação, verifica-se que apenas o lote 3 foi significativamente inferior aos demais. Por outro lado, a primeira contagem de germinação permitiu observar diferenças significativas entre os lotes, classificando-os em diferentes níveis de qualidade fisiológica. Neste teste, observa-se que o lote 5 foi classificado como superior, seguido pelo lote 6 , que não diferiu significativamente do lote 2 , sendo o lote 4 de qualidade inferior. A primeira contagem do teste de germinação, que reflete a velocidade de germinação das sementes e, portanto, o vigor, permitiu diferenciar o potencial fisiológico de lotes de sementes de cenoura (Spinola et al., 1998), pepino (Bhering et al., 2000),

TABELA 1. Caracterização da qualidade fisiológica de seis lotes de sementes de pimenta.

\begin{tabular}{cccc}
\hline Lote & $\begin{array}{c}\text { Germinação } \\
(\%)\end{array}$ & $\begin{array}{c}\text { Primeira } \\
\text { Contagem (\%) }\end{array}$ & $\begin{array}{c}\text { Germinação a Baixa } \\
\text { Temperatura (\%) }\end{array}$ \\
\hline 1 & $87,0 \mathrm{a}$ & $38,5 \mathrm{~cd}$ & $32,5 \mathrm{~b}$ \\
2 & $92,0 \mathrm{a}$ & $50,0 \mathrm{~b}$ & $75,5 \mathrm{a}$ \\
3 & $71,0 \mathrm{~b}$ & $37,0 \mathrm{~d}$ & $43,5 \mathrm{~b}$ \\
4 & $87,5 \mathrm{a}$ & $18,5 \mathrm{e}$ & $16,5 \mathrm{c}$ \\
5 & $93,0 \mathrm{a}$ & $85,0 \mathrm{a}$ & $84,5 \mathrm{a}$ \\
6 & $88,0 \mathrm{a}$ & $50,5 \mathrm{~b}$ & $46,0 \mathrm{~b}$ \\
\hline C.V.(\%) & 7,72 & 11,07 & 13,39 \\
\hline
\end{tabular}

$\mathrm{Na}$ coluna, médias seguidas da mesma letra minúscula não diferem entre si, pelo teste de Tukey, a 5\% de probabilidade. melancia (Bhering et al., 2003) e alface (Fanzin et al., 2004).

Já pelo teste de germinação a baixa temperatura, verificase melhor desempenho para as sementes dos lotes 5 e 2 , seguidas pelas dos lotes 1,3 e 6 , classificados como de qualidade fisiológica intermediária, confirmando o lote 4 como o de pior desempenho. Observa-se que este lote estava incluído entre os de melhor desempenho pelo teste padrão de germinação.

Pelo teste de envelhecimento acelerado a $38^{\circ} \mathrm{C}$ e $100 \%$ UR (Tabela 2), verifica-se, em todos os períodos estudados, maior vigor para o lote 5, seguido pelos lotes 6, 2, 3 e 1, com pior desempenho, em geral, para o lote 4. Quando se utilizou o método modificado ( $76 \%$ UR), no período de 48 horas, não houve diferença entre as sementes dos lotes 5 e 2, sendo que os lotes 1,3 e 6 foram classificados como de médio vigor, com menor vigor para o lote 4 , tendência esta que se manteve no período de 72 horas. Já no período de 96 horas, foi evidenciado o maior e o menor vigor para as sementes dos lotes 5 e 4, respectivamente, ficando os demais em posição intermediária. Assim, o lote 2 cujo vigor foi semelhante ao do lote 5 nos períodos de 48 e 72 horas, após 96 horas de envelhecimento foi classificado como de médio vigor, resultado este semelhante ao obtido na primeira contagem de germinação. Observa-se ainda, que após 96 horas de envelhecimento, no procedimento a $76 \%$ UR, não houve redução drástica na porcentagem de germinação quando comparado ao procedimento tradicional (100\% UR), devido ao menor grau de umidade alcançado pelas sementes e, provavelmente, à menor taxa de deterioração obtida no método modificado (76\% UR). A classificação dos lotes obtida no período de 48 foi similar à fornecida pelo teste de germinação a baixa temperatura (Tabela 1), indicando os lotes 2 e 5 como superiores aos demais. Portanto, os diferentes períodos de exposição das sementes ao teste de envelhecimento acelerado a $38^{\circ} \mathrm{C}$ apresentaram resultados semelhantes à primeira contagem de germinação e germinação a baixa temperatura, permitindo classificar os lotes quanto ao vigor. Em sementes de melão, Torres e Marcos Filho (2003) verificaram que o envelhecimento acelerado a $38^{\circ} \mathrm{C}$, tanto a $100 \%$ UR como a $76 \%$ UR, foi sensível para detectar diferenças na qualidade fisiológica dos lotes.

Nos testes de envelhecimento acelerado conduzidos a $42^{\circ} \mathrm{C}$ (Tabela 3 ), verifica-se que, no método tradicional $(100 \%$ UR), o período de 48 horas não proporcionou a separação eficiente dos lotes em níveis de vigor, indicando os lotes 3 e 5 como superiores, embora significativamente semelhantes aos lotes 1 e 2, com pior desempenho para o lote 4 . No período 
de 72 horas, também se destacaram os lotes 5 e 3, com pior desempenho para os lotes 4 e 6. Quando as sementes foram envelhecidas por 96 horas, obteve-se classificação dos lotes similar à obtida na primeira contagem de germinação (Tabela 1), com melhor e pior desempenho para os lotes 5 e 4 , respectivamente e desempenho intermediário para os lotes 2 e 6. Segundo Marcos Filho (1999), a identificação do potencial fisiológico dos lotes de médio vigor é muitas vezes mais difícil, pois estes lotes podem apresentar variações no seu comportamento, ora se igualando aos lotes de maior vigor, ora aos de menor vigor, dependendo do teste de vigor empregado.

Os resultados referentes ao uso da solução saturada de $\mathrm{NaCl}(76 \% \mathrm{UR}), \mathrm{a} 42^{\circ} \mathrm{C}$ por 48 horas foram semelhantes aos obtidos no mesmo período a $42^{\circ} \mathrm{C}$ e $100 \%$ UR (Tabela 3 ). Já no período de 72 horas, houve melhor estratificação dos lotes, sendo os lotes 5 e 4 , respectivamente, superior e inferior aos demais, os quais não diferiram entre si. Nota-se que esta classificação foi semelhante à obtida $42^{\circ} \mathrm{C}$ no período de 72 horas pelo método tradicional. Após 96 horas de envelhecimento, o melhor desempenho do lote 5 foi confirmado, seguido pelo lote 2, com menor vigor para o lote 4 .

Ainda na Tabela 3, nota-se que os valores obtidos com o uso de solução salina foram, em geral, superiores aos do método tradicional, o que pode ser explicado pelos menores teores de água (Tabela 5) atingidos pelas sementes no método modificado ( $76 \%$ UR). Verifica-se que o teor de água máximo atingido pelas sementes nesse método foi de $13,8 \%$, mesmo quando associado às temperaturas elevadas, o que refletiu em menor taxa de deterioração as mesmas. No entanto, este fato não impediu a classificação dos lotes quanto ao vigor, promovendo estresse suficiente para esta finalidade. Ribeiro e Carvalho (2001), trabalhando com sementes de cenoura, alface e brócolis, observaram que o controle da umidade relativa do ar no interior dos gerbox, mediante o uso de soluções saturadas de $\mathrm{NaCl}$ e $\mathrm{KCl}$, não foi eficiente para a avaliação do vigor. Também, Bhering et al. (2003) com sementes de melancia e Carpi (2005) com rabanete não

TABELA 2. Germinação (\%) de sementes de seis lotes de pimenta após os testes de envelhecimento acelerado tradicional (EA-100\% UR) e modificado (EA-76\% UR), conduzidos a $38^{\circ} \mathrm{C}$, em diferentes períodos de tempo.

\begin{tabular}{|c|c|c|c|c|c|c|}
\hline \multirow[b]{2}{*}{ Lote } & \multicolumn{3}{|c|}{ EA tradicional } & \multicolumn{3}{|c|}{ EA modificado } \\
\hline & $48 \mathrm{~h}$ & $72 \mathrm{~h}$ & $96 \mathrm{~h}$ & $48 \mathrm{~h}$ & $72 \mathrm{~h}$ & $96 \mathrm{~h}$ \\
\hline 1 & $57,5 \mathrm{bc}$ & $80,5 \mathrm{ab}$ & $62,0 \mathrm{c}$ & $73,0 b$ & $87,0 \mathrm{~b}$ & $78,0 \mathrm{bc}$ \\
\hline 2 & $66,0 \mathrm{~b}$ & $80,0 \mathrm{ab}$ & $75,5 \mathrm{~b}$ & $87,5 \mathrm{a}$ & $89,0 \mathrm{ab}$ & $82,0 \mathrm{bc}$ \\
\hline 3 & $63,5 \mathrm{bc}$ & $84,5 \mathrm{ab}$ & $65,5 \mathrm{bc}$ & $74,0 \mathrm{~b}$ & $67,5 \mathrm{c}$ & $71,5 \mathrm{c}$ \\
\hline 4 & $49,0 \mathrm{c}$ & $44,5 \mathrm{c}$ & $46,0 \mathrm{~d}$ & $57,5 \mathrm{c}$ & $60,0 \mathrm{~d}$ & $46,0 \mathrm{~d}$ \\
\hline 5 & $93,5 \mathrm{a}$ & $95,0 \mathrm{a}$ & $91,0 \mathrm{a}$ & $95,5 \mathrm{a}$ & $94,0 \mathrm{a}$ & $96,0 \mathrm{a}$ \\
\hline 6 & $70,0 \mathrm{~b}$ & $73,0 \mathrm{~b}$ & $64,0 \mathrm{c}$ & $73,5 \mathrm{~b}$ & $85,0 \mathrm{~b}$ & $83,0 \mathrm{~b}$ \\
\hline C.V. $(\%)$ & 11,1 & 11,4 & 7,3 & 6,4 & 3,6 & 6,4 \\
\hline
\end{tabular}

Na coluna, médias seguidas da mesma letra minúscula não diferem entre si, pelo teste de Tukey, a 5\% de probabilidade.

TABELA 3. Germinação (\%) de sementes de seis lotes de pimenta após os testes de envelhecimento acelerado tradicional (EA $100 \%$ UR) e modificado (EA-76\% UR), conduzidos a $42^{\circ} \mathrm{C}$, em diferentes períodos de tempo.

\begin{tabular}{|c|c|c|c|c|c|c|}
\hline \multirow[b]{2}{*}{ Lote } & \multicolumn{3}{|c|}{ EA tradicional } & \multicolumn{3}{|c|}{ EA modificado } \\
\hline & $48 \mathrm{~h}$ & $72 \mathrm{~h}$ & $96 \mathrm{~h}$ & $48 \mathrm{~h}$ & $72 \mathrm{~h}$ & $96 \mathrm{~h}$ \\
\hline 1 & $62,0 \mathrm{ab}$ & $49,0 \mathrm{~b}$ & $33,0 \mathrm{bc}$ & $77,5 \mathrm{~b}$ & $72,0 \mathrm{~b}$ & $70,0 \mathrm{bc}$ \\
\hline 2 & $71,0 \mathrm{ab}$ & $49,0 \mathrm{~b}$ & $46,0 \mathrm{~b}$ & $79,0 \mathrm{ab}$ & $71,5 \mathrm{~b}$ & $75,0 \mathrm{~b}$ \\
\hline 3 & $79,0 \mathrm{a}$ & $56,0 \mathrm{ab}$ & $23,0 \mathrm{bc}$ & $80,5 \mathrm{ab}$ & $56,0 \mathrm{~b}$ & $65,0 \mathrm{c}$ \\
\hline 4 & $26,0 \mathrm{c}$ & $21,0 \mathrm{c}$ & $10,0 \mathrm{c}$ & $48,0 \mathrm{c}$ & $27,0 \mathrm{c}$ & $28,0 \mathrm{~d}$ \\
\hline 5 & $80,0 \mathrm{a}$ & $75,0 \mathrm{a}$ & 89,0 a & $92,0 \mathrm{a}$ & $91,5 \mathrm{a}$ & $89,5 \mathrm{a}$ \\
\hline 6 & $58,0 \mathrm{~b}$ & $39,0 \mathrm{bc}$ & $38,0 \mathrm{~b}$ & $74,0 \mathrm{~b}$ & $72,5 \mathrm{~b}$ & $64,0 \mathrm{c}$ \\
\hline C.V. $(\%)$ & 14,4 & 22,4 & 28,3 & 8,2 & 11,6 & 6,4 \\
\hline
\end{tabular}

Na coluna, médias seguidas da mesma letra minúscula não diferem entre si, pelo teste de Tukey, a 5\% de probabilidade. 
obtiveram separação eficiente de lotes quanto ao vigor, utilizando solução de $\mathrm{NaCl}$. Em contrapartida, Rodo et al. (2000) com sementes de cenoura, Torres e Marcos Filho (2003) com melão e Rodo e Marcos Filho (2003) com cebola verificaram que o uso de solução salina proporcionou resultados mais uniformes em relação ao procedimento convencional, sem afetar a eficiência do teste. Por sua vez, Panobianco e Marcos Filho (2001) e Dutra (2004) constataram que ambos os procedimentos, convencional e modificado, permitiram a classificação dos lotes de tomate e abóbora, respectivamente, em níveis de vigor, indicando como mais adequada a combinação de $41^{\circ} \mathrm{C}$ por 72 horas.

Quando se utilizou a temperatura de $45^{\circ} \mathrm{C}$ e $100 \%$ UR (Tabela 4), houve redução drástica nos valores de germinação de todos os lotes após o envelhecimento por 72 e 96 horas, ocorrendo praticamente a morte das sementes dos lotes 2 e 4 no período de 72 horas e dos lotes 2, 4 e 6 , no período de 96 horas. Portanto, a elevação da temperatura do teste para $45^{\circ} \mathrm{C}$ aliada a maiores períodos de envelhecimento foi inadequada para a avaliação segura dos lotes de média e baixa qualidade fisiológica, dificultando a separação destes. No período de 48 horas, foi possível separar os lotes quanto ao seu desempenho fisiológico, destacando-se o lote 5 como superior, seguido pelos lotes 6, 2 e 3, com menor vigor para os lotes 1 e 4, embora estes não tenham diferido significativamente dos lotes 2 e 3 . Assim, nesta condição, não houve separação eficiente dos lotes quanto ao vigor, sendo possível apenas destacar a superioridade do lote 5 em relação aos demais. Observa-se ainda que os coeficientes de variação obtidos nos períodos de 72 e 96 horas foram elevados, em função da queda drástica da germinação das sementes dos lotes 1,2, 3 e 6, com grande variação entre as repetições. De acordo com Tomes et al. (1988), a elevação da temperatura no teste de envelhecimento promove efeitos mais drásticos na germinação do que o prolongamento do período de exposição ao envelhecimento. Observa-se, neste trabalho, que a exposição das sementes à temperatura de $45^{\circ} \mathrm{C}$ no método tradicional, principalmente quando associada aos períodos de 72 e 96 horas, reduziu drasticamente a germinação quando comparada a 38 e $42^{\circ} \mathrm{C}$. Observa-se que 72 horas de exposição a $45^{\circ} \mathrm{C}$ e $100 \%$ UR foram suficientes para provocar a morte das sementes dos lotes 2 e 4 . Resultados semelhantes foram observados por Ramos et al. (2004) com sementes de rúcula.

$\mathrm{O}$ uso de solução saturada de $\mathrm{NaCl}$ a $45^{\circ} \mathrm{C}$ por 48 horas (Tabela 4) permitiu classificar os lotes em diferentes níveis de vigor, indicando o lote 5 como de maior vigor, seguido pelos lotes 1,2 e 3 que foram superior aos lotes 4 e 6 , sendo o lote 4 o de menor vigor. Classificação semelhante foi obtida nos períodos de 72 e 96 horas (76\% UR), com maior vigor para o lote 5 e menor vigor para o lote 4 , que não diferiu do lote 1 . Nota-se que este lote foi classificado pela primeira contagem de germinação e germinação a baixa temperatura como de qualidade intermediária. Portanto, em geral, a temperatura de $45^{\circ} \mathrm{C}$ não permitiu a classificação adequada dos lotes em níveis de vigor, além de proporcionar grande variação entre repetições. Demir et al. (2004), testando o método tradicional a 40 e $45^{\circ} \mathrm{C}$, por diferentes períodos de tempo, observaram que o uso de $45^{\circ} \mathrm{C}$ por 72 horas foi eficiente para avaliar o vigor de sementes de berinjela e abóbora, enquanto para melão a condição de envelhecimento mais indicada foi $45^{\circ} \mathrm{C}$ por 120 horas.

Os dados referentes ao grau de umidade das sementes antes e após o envelhecimento acelerado encontram-se na Tabela 5. Verifica-se que o teor de água inicial das sementes dos seis lotes foi semelhante, variando de 9,8 a 10,2\%. A comparação de amostras que apresentem grau de umidade

TABELA 4. Germinação (\%) de sementes de seis lotes de pimenta após os testes de envelhecimento acelerado tradicional (EA-100\% UR) e modificado (EA-76\% UR), conduzidos a $45^{\circ} \mathrm{C}$, em diferentes períodos de tempo.

\begin{tabular}{|c|c|c|c|c|c|c|}
\hline \multirow{2}{*}{ Lote } & \multicolumn{3}{|c|}{ EA tradicional } & \multicolumn{3}{|c|}{ EA modificado } \\
\hline & $48 \mathrm{~h}$ & $72 \mathrm{~h}$ & $96 h$ & $48 \mathrm{~h}$ & $72 \mathrm{~h}$ & $96 h$ \\
\hline 1 & $29,0 \mathrm{c}$ & $7,5 \mathrm{bc}$ & $7,5 \mathrm{~b}$ & $70,0 \mathrm{bc}$ & $43,0 \mathrm{bc}$ & $41,0 \mathrm{bc}$ \\
\hline 2 & $41,0 \mathrm{bc}$ & $1,0 \mathrm{c}$ & $1,0 \mathrm{~b}$ & $72,0 \mathrm{~b}$ & $52,0 \mathrm{~b}$ & $52,0 \mathrm{~b}$ \\
\hline 3 & $38,0 \mathrm{bc}$ & $11,0 \mathrm{~b}$ & $27,0 \mathrm{a}$ & $70,0 \mathrm{bc}$ & $52,0 \mathrm{~b}$ & $57,0 \mathrm{~b}$ \\
\hline 4 & $21,0 \mathrm{c}$ & $1,0 \mathrm{c}$ & $5,0 \mathrm{~b}$ & $26,0 \mathrm{~d}$ & $28,0 \mathrm{c}$ & $25,0 \mathrm{c}$ \\
\hline 5 & $82,0 \mathrm{a}$ & $40,5 \mathrm{a}$ & $36,0 \mathrm{a}$ & $90,6 \mathrm{a}$ & 83,0 a & 89,0 a \\
\hline 6 & $58,0 \mathrm{~b}$ & $9,0 \mathrm{bc}$ & $1,5 \mathrm{~b}$ & $57,0 \mathrm{c}$ & $58,0 \mathrm{~b}$ & $54,0 \mathrm{~b}$ \\
\hline C.V. $(\%)$ & 22,5 & 32,3 & 31,8 & 9,7 & 13,3 & 17,0 \\
\hline
\end{tabular}

Na coluna, médias seguidas da mesma letra minúscula não diferem entre si, pelo teste de Tukey, a 5\% de probabilidade. 
semelhantes antes do envelhecimento acelerado é conveniente, embora diferenças de até dois pontos porcentuais (pp) no grau de umidade inicial das sementes não sejam comprometedoras (Marcos Filho, 1999). Verifica-se, neste trabalho, que a maior diferença observada foi de $0,4 \mathrm{pp}$, estando, portanto, dentro deste limite. Após 48 horas de envelhecimento pelo método tradicional ( $100 \%$ UR) verificou-se em geral que as sementes absorveram água, atingindo valores entre 22,0 a $26,3 \%$ a $38^{\circ} \mathrm{C}$ e entre 24,0 e $26,9 \%$ a $42^{\circ} \mathrm{C}$, com elevação destes valores com o aumento da temperatura para $45^{\circ} \mathrm{C}$ (entre 33,4 e 36,4\%). Observa-se, portanto, que a variação no teor de água das amostras foi de, no máximo, 4,3pp. O aumento do período de envelhecimento para 72 horas proporcionou aumento no teor de água das sementes, com as maiores variações observadas, ou seja, $4,6 \mathrm{pp}$ a $38^{\circ} \mathrm{C}$ e a $4,9 \mathrm{pp} 42^{\circ} \mathrm{C}$ e $4,0 \mathrm{pp}$ a $45^{\circ} \mathrm{C}$. No período de 96 horas, apenas ã temperatura de $42^{\circ} \mathrm{C}$ a variação excedeu àquelas observadas no período de $72 \mathrm{~h}$, atingindo 5,9pp.
O grau de umidade das sementes após o envelhecimento acelerado é um dos principais indicadores da uniformidade das condições de envelhecimento, pois variações de três a quatro pontos percentuais entre amostras são toleráveis (Marcos Filho, 1999). Verifica-se, que na maioria das condições estudadas neste trabalho, a variação entre o teor de água das sementes dos seis lotes permaneceu, em geral, dentro do limite tolerável.

Quando se utilizou solução saturada de $\mathrm{NaCl}$ (Tabela 5), as variações no teor de água dos diferentes lotes foi bem menor e os teores de água atingidos após o envelhecimento permaneceram próximos aos valores iniciais, indicando que a umidade relativa de $76 \%$ retardou a absorção de água pelas sementes, conforme proposto por Jianhua e McDonald (1997). Estes autores consideram a limitação na absorção de água uma alternativa interessante para a avaliação do vigor de sementes de hortaliças, cujas sementes pequenas absorvem água mais rápida e desuniformemente, o que pode resultar

TABELA 5. Grau de umidade inicial e após diferentes períodos de envelhecimento acelerado pelo método tradicional (100\% UR) e modificado ( $76 \% \mathrm{UR}$ ) a 38,42 e $45^{\circ} \mathrm{C}$.

\begin{tabular}{|c|c|c|c|c|c|c|c|}
\hline \multirow{2}{*}{ Lote } & \multirow{2}{*}{ GU Inicial } & \multicolumn{3}{|c|}{$100 \% \mathrm{UR}-38^{\circ} \mathrm{C}$} & \multicolumn{3}{|c|}{$76 \%$ UR $-38^{\circ} \mathrm{C}$} \\
\hline & & $48 \mathrm{~h}$ & $72 \mathrm{~h}$ & $96 \mathrm{~h}$ & $48 \mathrm{~h}$ & $72 \mathrm{~h}$ & $96 \mathrm{~h}$ \\
\hline 1 & 10,2 & 22,0 & 31,0 & 35,3 & 11,1 & 13,0 & 12,5 \\
\hline 2 & 10,1 & 22,0 & 35,2 & 31,6 & 11,5 & 11,4 & 11,2 \\
\hline 3 & 9,8 & 22,2 & 35,6 & 35,0 & 12,4 & 13,0 & 11,6 \\
\hline 4 & 9,9 & 26,3 & 31,3 & 31,5 & 13,4 & 12,5 & 10,8 \\
\hline 5 & 10,0 & 22,4 & 32,7 & 31,8 & 13,8 & 13,0 & 11,5 \\
\hline \multirow[t]{3}{*}{6} & 10,1 & 24,9 & 31,7 & 33,5 & 12,1 & 13,1 & 11,6 \\
\hline & & \multicolumn{3}{|c|}{$100 \% \mathrm{UR}-42^{\circ} \mathrm{C}$} & \multicolumn{3}{|c|}{$76 \%$ UR $-42^{\circ} \mathrm{C}$} \\
\hline & & $48 \mathrm{~h}$ & $72 \mathrm{~h}$ & $96 \mathrm{~h}$ & $48 \mathrm{~h}$ & $72 \mathrm{~h}$ & $96 \mathrm{~h}$ \\
\hline 1 & & 25,0 & 32,2 & 37,1 & 11,6 & 11,3 & 10,1 \\
\hline 2 & & 24,0 & 32,9 & 36,8 & 10,5 & 10,3 & 10,1 \\
\hline 3 & & 26,0 & 35,0 & 33,1 & 11,9 & 11,8 & 11,3 \\
\hline 4 & & 24,0 & 36,7 & 36,7 & 10,3 & 11,9 & 10,8 \\
\hline 5 & & 24,7 & 36,0 & 32,5 & 11,0 & 11,5 & 10,6 \\
\hline 6 & & 26,9 & 31,8 & 31,2 & 10,7 & 11,0 & 12,0 \\
\hline \multirow{2}{*}{ Lote } & & \multicolumn{3}{|c|}{$100 \% \mathrm{UR}-45^{\circ} \mathrm{C}$} & \multicolumn{3}{|c|}{$76 \%$ UR $-45^{\circ} \mathrm{C}$} \\
\hline & & $48 \mathrm{~h}$ & $72 \mathrm{~h}$ & $96 \mathrm{~h}$ & $48 \mathrm{~h}$ & $72 \mathrm{~h}$ & $96 \mathrm{~h}$ \\
\hline 1 & & 33,4 & 36,0 & 36,3 & 11,8 & 11,7 & 11,4 \\
\hline 2 & & 34,7 & 33,1 & 36,7 & 11,1 & 10,9 & 10,5 \\
\hline 3 & & 34,4 & 32,0 & 35,1 & 10,7 & 11,4 & 11,3 \\
\hline 4 & & 36,4 & 35,2 & 36,4 & 11,0 & 11,7 & 10,7 \\
\hline 5 & & 36,2 & 34,9 & 33,5 & 10,4 & 10,6 & 10,2 \\
\hline 6 & & 35,8 & 35,8 & 35,9 & 9,7 & 10,7 & 10,4 \\
\hline
\end{tabular}


em comportamento variado entre as sementes de mesmo lote. Assim, o uso de solução salina promoveu efeito menos drástico nas sementes, pois ao atingir menores teores de água (máximo de $13,8 \% 38^{\circ} \mathrm{C} / 48 \mathrm{~h}$ enquanto no método tradicional chegou a $37,1 \% 42^{\circ} \mathrm{C} / 96 \mathrm{~h}$ ), o grau de deterioração foi menor em relação ao provocado pelo método tradicional.

\section{CONCLUSÕES}

O teste de envelhecimento acelerado é eficiente para a avaliação do vigor de sementes de pimenta.

O envelhecimento acelerado a 38 ou $42^{\circ} \mathrm{C}$ por 96 horas, tanto pelo método tradicional como pelo método modificado, fornece informações semelhantes aos testes de primeira contagem de germinação e germinação a baixa temperatura, permitindo classificar os lotes em diferentes níveis de vigor.

\section{REFERÊNCIAS}

ASSOCIATION OF OFFICIAL SEED ANALYSTS. Seed vigor testing handbook. East Lansing, 1983. 88p. (Contribuition, 32).

BENNETT, M.; BARR, A.; GRASSBAUGH, E.M.; EVANS, A.F. Seed vigor evaluation of su, se, and sh2 sweet corn genotypes using the saturated salt accelerated aging test. In: INTERNATIONAL SEED TESTING CONGRESS, 25. 1998, Pretoria. Abstracts... Pretoria: ISTA, 1998. p.92-93.

BHERING, M.C.; DIAS, D.C.F.S.; BARROS, D.I.; TOKUHISA, D. Avaliação do vigor de sementes de melancia (Citrullus lanatus Scherad.) pelo teste de envelhecimento acelerado. Revista Brasileira de Sementes, Londrina, v.25, n.2, p.1-6, 2003.

BHERING, M.C.; DIAS, D.C.F.S.; GOMES, J.M.; BARROS, D.I. Métodos para avaliação do vigor de sementes de pepino. Revista Brasileira de Sementes, Londrina, v.22, n.2, p.171-175, 2000.

BRASIL. Ministério da Agricultura e Reforma Agrária. Regras para análise de sementes. Brasília: SNDA/DNDV/CLAV, 1992. 365p.

CARPI, V.A.F. Avaliação do potencial fisiológico de sementes de rabanete (Raphanus sativus L.). 2005. 77f. Tese (Doutorado em Agronomia) - Escola Superior de Agricultura "Luiz de Queiroz", Universidade de São Paulo, Piracicaba, 2005.

DELOUCHE, J.C.; BASKIN, C.C. Accelerated aging techniques for predicting the relative storability of seed lots. Seed Science and Technology, Zürich, v.1, n.3, p.427-452, 1973.

DEMIR, I.; OZDEN, Y.S.; YILMAZ, K. Accelerated ageing test of aubergine, cucumber and melon seeds in relation to time and temperature variables. Seed Science and Technology, Zürich, v.32, p.851-855, 2004.

DIAS, D.C.F.S.; ALVARENGA, E.M. Teste de germinação a baixa temperatura. In: KRZYZANOWSKI, F.C.; VIEIRA, R.D.; FRANÇA NETO, J.B. (Eds.) Vigor de sementes: conceitos e testes. Londrina: ABRATES, 1999. cap.7, p.1-4.
DUTRA, A.S. Avaliação do potencial fisiológico de sementes de abóbora e abobrinha. 2004. 76f. Tese (Doutorado em Agronomia) - Faculdade de Ciências Agrárias e Veterinárias, Universidade Estadual Paulista, Jaboticabal, 2004.

FRANZIN, S.M.; MENEZES, N.L.; GARCIA, D.C.; ROVERSI, T. Avaliação do vigor de sementes de alface nuas e peletizadas. Revista Brasileira de Sementes, Pelotas, v.26, n.2, p.114-118, 2004.

JIANHUA, Z.; McDONALD, M.B. The saturated salt accelerated aging test for small-seeded crops. Seed Science and Technology, Zürich, v.25, n.1, p.123-131, 1997.

MARCOS FILHO, J. Teste de envelhecimento acelerado. In: KRZYZANOWSKI, F.C.; VIEIRA, R.D.; FRANÇA NETO, J.B. (Eds.) Vigor de sementes: conceitos e testes. Londrina: ABRATES, Comitê de Vigor de Sementes, 1999. cap.3, p.1-24.

MELLO, V.D.C.; TILLMANN, M.A.A. O teste de vigor em câmara de envelhecimento precoce. In: CONGRESSO BRASILEIRO DE SEMENTES, 5.1987.Gramado, Resumos... Brasília: ABRATES, 1987. p.85.

PANOBIANCO, M.; MARCOS FILHO, J. Comparação entre métodos para avaliação da qualidade fisiológica de sementes de pimentão. Revista Brasileira de Sementes, Brasília, v.20, n.2, p.306-310, 1998.

PANOBIANCO, M.; MARCOS FILHO, J. Envelhecimento acelerado e deterioração controlada em sementes de tomate. Scientia Agricola, Piracicaba, v.58, n.3, p.525-531, 2001.

PIANA, Z.; TILLMANN, M.A.A.; MINAMI, K. Avaliação da qualidade fisiológica de sementes de cebola e sua relação com a produção de mudas vigorosas. Revista Brasileira de Sementes, Brasília, v.20, n.2, p.301-305, 1998.

RAMOS, N.P.; FLOR, E.P.O.; MENDONÇA, E.A.F.; MINAMI, K. Envelhecimento acelerado em sementes de rúcula (Eruca sativa L.). Revista Brasileira de Sementes, Pelotas, v.26, n.1, p.98-103, 2004.

RIBEIRO, F.C. Comparação entre os sistemas de envelhecimento artificial de sementes através de soluções salinas e o tradicional em cenoura (Daucus carota $\mathbf{L}$.), alface (Lactuca sativa $\mathbf{L}$.) e brócolos (Brassica oleracea variedade etálica Plenk.). 2000. $56 \mathrm{f}$. Dissertação (Mestrado em Agronomia) - Faculdade de Ciências Agrárias e Veterinárias, Universidade Estadual Paulista, Jaboticabal, 2000.

RIBEIRO, F.C.; CARVALHO, N.M. The saturated salt accelerated aging method seems to act lencentry on carrot, lettuce and broccoli seeds germination. In: INTERNATIONAL SEED TESTING CONGRESS - SEED SYMPOSIUM, 26., 2001, Angers. Abstracts... Zürich: ISTA, 2001, p.39-40.

RODO, A.B.; MARCOS FILHO, J. Accelerated aging and controlled deterioration for the determination of the physiological potential of onion seeds. Scientia Agricola, Piracicaba, v.60, n.3, p.465-469, 2003.

RODO, A.B.; PANOBIANCO, M.; MARCOS FILHO, J. Metodologia alternativa do teste de envelhecimento acelerado para sementes de cenoura. Scientia Agricola, Piracicaba, v.57, n.2, p.289-292, 2000.

RODO, A.B.; TILLMANN, M.A.A.; VILLELA, F.A. Testes de vigor na avaliação da qualidade fisiológica de sementes de tomate. 
Revista Brasileira de Sementes, Londrina, v.20, n.1, p.23-38, 1998. SPINOLA, M.C.M.; CALIARI, M.F.; MARTINS, L.; TESSARIOLI NETO, J. Comparação entre métodos para avaliação do vigor de sementes de cenoura. Revista Brasileira de Sementes, Brasília, v.20, n.2, p.301-305, 1998 .

TOMES, L.J.; TEKRONY, D.M.; EGLI, D.B. Factors influencing the tray accelerated aging test for soybean seed. Journal of Seed
Technology, East Lansing, v.12, n.1, p.24-35, 1988.

TORRES, S.B.; CARVALHO, I.M.S. Teste de envelhecimento acelerado em sementes de quiabo (Albelmoschus esculentus (L.) Moench). Revista Brasileira de Sementes, Brasília, v.20, n.1, p.209-211, 1998.

TORRES, S.B.; MARCOS FILHO, J. Accelerated aging of melon seeds. Scientia Agricola, Piracicaba, v.60, n.1, p.77-82, 2003.

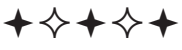

